\title{
APPLICATION OF EQUIVALENT MATERIALS TO MODELING FRACTURES IN THE VICINITY OF A NORMAL FAULT IN THE AREA OF MINING EXPLOITATION INFLUENCE
}

\author{
Pu WANG ${ }^{1}$, Lishuai JIANG ${ }^{1}$ * and Pengqiang ZHENG $^{2}{ }^{2}$ * \\ ${ }^{1)}$ State Key Laboratory of Mining Disaster Prevention and Control Co-founded by Shandong Province and the Ministry of Science and \\ Technology, Shandong University of Science and Technology, Qingdao 266590, China \\ 2) Department of Resources and Civil Engineering, Shandong University of Science and Technology, Tai'an, 271019, China
}

*Corresponding author's e-mail: skwp0701@foxmail.com; pqzheng_1231@163.com

\section{ARTICLE INFO}

\section{Article history}

Received 6 July 2017

Accepted 23 October 2017

Available online 7 November 2017

\section{Keywords:}

Equivalent materials

Physical simulation test

Fault activation

Mining-induced fracture

\begin{abstract}
The study of mining-induced behaviors of faults and strata in underground coalmines is significant to know the mechanism and prediction of some accidents (i.e., water inrush, gas flowing and outburst). Equivalent materials are applied herein in an underground project to simulate a progressive mining operation with a normal fault occurrence. The failure-movement evolution of the overlying strata and the stress-displacement evolution of the fault are studied through a physical simulation test. The formation of a mining-induced fracture and the mechanism of accidents caused by the mining-induced fracture are analyzed. The results show that the footwall strata underwent a more notable movement compared to the hanging wall strata. Hence, the mining-induced fracture height of the footwall is higher than that of the hanging wall. The effect of the fault can be observed on the mining-induced fracture evolution of the footwall, hanging wall, and fault plane. The developed patterns of the fracture channel successively present an evolution in the shape of a "saddle", a "trapezium", and an " $M$ ". The causes of accidents induced by the mining fracture are also discussed.
\end{abstract}

\section{INTRODUCTION}

The failure extent and intensity of mininginduced overlying strata behaviors have dramatically increased with the expansion of mining activities, leading to some hazardous accidents, such as roof water inrush, gas flowing and outburst. This effect would even be more significant with the existence of faults caused by the mining-induced fault activation and mining-induced fracture development (Ding et al., 2014; Wang et al., 2016). For instance, a roof water inrush accident (2001) occurred in Dongtan coalmine when the retreat-working face of panel 14301 passed $8 \mathrm{~m}$ from a normal fault (NF9) (Fig. 1a; (Hu, 2008)). Two roof water inrush accidents (2000 and 2001) also occurred in Xinji No. 1 coalmine when the coal of panel 111311 was extracted in retreat within a region of two normal faults (F078 and F038) (Fig. 1b; (Wang and Ding, 2002)).

In view of the formation mechanism of faults (Blenkinsop, 2008), normal faults tend to failure in tension and have a stronger permeability and water inrush or gas outburst potential compared to reverse faults. Hence, this study focuses on the fracturemovement characteristics and the mining-induced fracture evolution of the overlying strata with the existence of a normal fault.

Considerable studies have been conducted using different methods to estimate the mining-induced strata behavior and hazard potential with the influence of faults. $\mathrm{Hu}$ (2008), Yin et al. (2009) and Zhen et al. (2013) employed the methods of physical and numerical simulations and theoretical analysis to study the breaking and movement characteristics of the overlying strata influenced by faults. Consequently, they obtained the evolutionary laws of strata breaking and stress distribution. In terms of the mining-induced fracture evolution, the evolution process of structural fracture and the mining-induced fractured zone induced by the fault activation were investigated through physical and numerical simulations. Previous studies concluded that the extension and dip of faults have a significant effect on the height of the mining-induced fractured zone (Huang et al., 2009; Fan, 2014a, 2014b). Jiang et al. (2017), Yin et al. (2017) and Lin (2009) studied the evolution characteristics of the overlying mininginduced fracture and its effect on gas migration through similar material simulation tests and numerical simulation.

Previous studies also involved considerable research on fault activation or mining-induced fracture evolution. However, the evolution characteristics of a mining-induced fracture, the formation of a fracture channel from the development and connection of the mining-induced fracture, and their coupling effect with overlying strata movement remain to be investigated. 


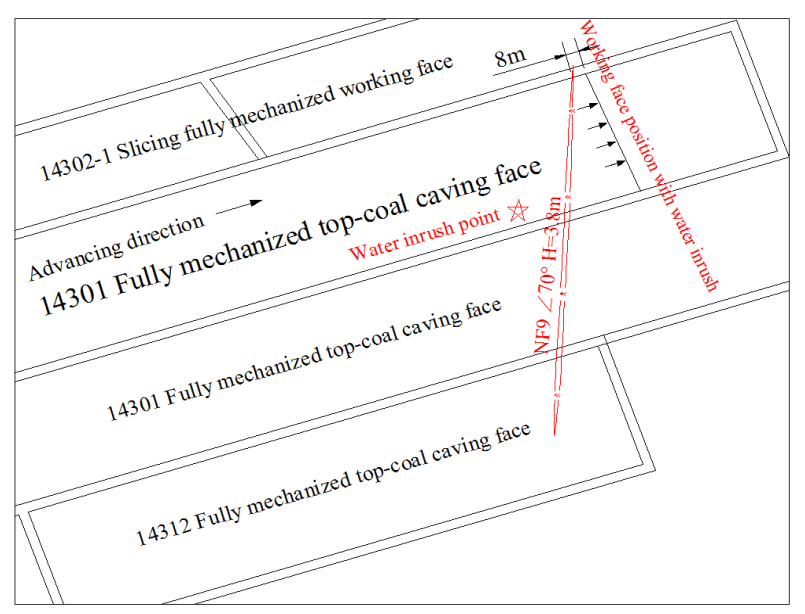

(a)

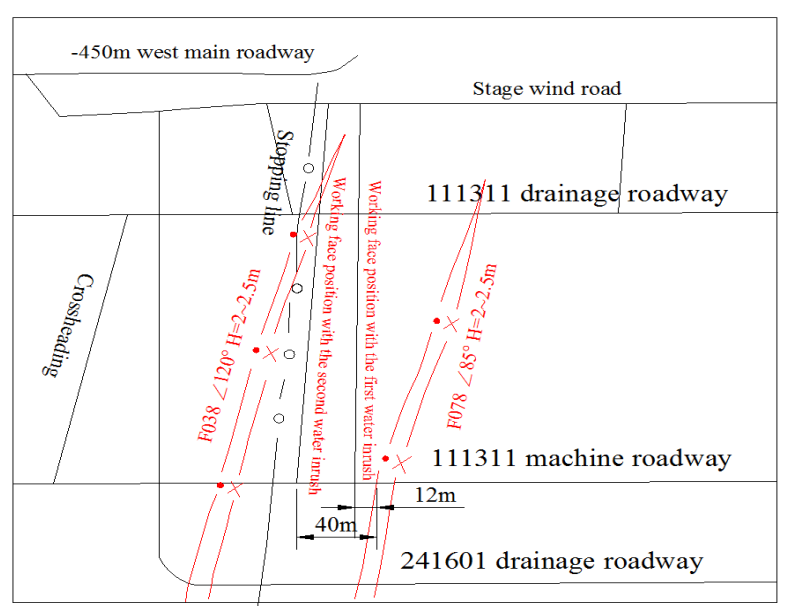

(b)

Fig. 1 Cases of roof water inrush: (a) panel 14301 in the Dongtan mine and (b) panel 111311 in No. 1 Xinji mine.

In addition to the high cost and time consumption of field measurements that make it unsuitable for comprehensive investigation, stress readjustment and fracture propagation are also extremely difficult for on-site observation and monitoring because of the inaccessibility of overlying strata (Huang et al., 2011; Liu et al., 2011; Jiang et al., 2016). Many researchers employed the research methodology of the similar material simulation test for the mining-induced strata movement (Huang et al., 2011; Liu et al., 2011; Zhou et al., 2014; Wang et al., 2015a). Thus, they overcame the aforementioned limitations and contributed to the visualization of the evolution procedure. Hence, the present study investigates the mining-induced failure-movement evolution of the overlying strata and the stressdisplacement evolution of the fault by employing a physical simulation test. This study also analyzes the formation of a fracture channel based on a physical simulation of a progressive mining operation in a fault-affected region.

\section{SCHEME AND DESIGN OF THE PHYSICAL SIMULATION TEST}

The physical simulation method developed based on the similarity theory and dimensional analysis can be easily practiced, has a short model-making cycle, and has been widely used in mining research in the related research of the mining industry in the US, Australia, China, and Poland, among other countries (Wang et al., 2015a).

\subsection{PHYSICAL MODEL}

The construction of the physical model needs to follow the similarity criteria in geometry, mechanical properties, and boundary conditions (Xie et al., 2016). The model frame must be rigid to ensure the stability of the model, whose geometric dimensions (length $\times$ width $\times$ height) are $3000 \mathrm{~mm} \times 400 \mathrm{~mm} \times 1800 \mathrm{~mm}$ (Fig. 2). The test system mainly includes three parts: frame, loading, and monitoring systems. According to the size of the frame system and the simulating target, the whole strike length of the model is $2250 \mathrm{~mm}$.
Hence, the geometric similarity ratio is $C_{l}=1 / 200$, which could simulate the actual size (length: $450 \mathrm{~m}$ ). According to previous studies, the density similarity ratio $C_{\rho}$ describing the properties of the simulation material and the rock mass similar ratio ranges from 0.64 to 1.67 (Dai et al., 2010; Wang et al., 2015a; Lai et al., 2016; Xie et al., 2016). Thus, it is reasonably determined as $C_{\rho}=\rho_{m} / \rho_{r}=1 / 1.5$, where $\rho_{m}$ is the density of the physical model, and $\rho_{r}$ is the density of the in-situ rock mass. The strength similarity ratio can be obtained as $C_{\sigma}=C_{l} \cdot C_{\rho}=1 / 300$ (Dai et al., 2010; $\mathrm{Xie}$ et al., 2016). The main characteristics of the insitu model are as follows: the coal seam thickness is $8 \mathrm{~m}$; the dip angle of the normal fault is $50^{\circ}$; and the fall of fault is $4 \mathrm{~m}$. Table 1 presents the properties of the in-situ and physical model.

A normal fault and a reverse fault are laid in the test model. Only the normal fault is the research object in this study. The depth of the excavation face is approximately $270 \mathrm{~m}$. The simulated mining depth of the physical model is approximately $1100 \mathrm{~mm}$; hence, the other $50 \mathrm{~m}$ of the overlying strata of the insitu model is not simulated. Consequently, some iron needs to be imposed on top of the model to compensate. Therefore, the total iron quality can be calculated as follows using Eq. (1):

$\sigma_{m}=\frac{\rho g h}{C_{\rho} \cdot C_{l}}, \quad m=\frac{\sigma_{m} \cdot S_{m}}{g}$,

where $\sigma_{m}$ is the compensating load of the model, $\mathrm{Pa}$; $\rho$ is the average density of the failed lay strata on the in-situ model, $2500 \mathrm{~kg} / \mathrm{m}^{3} ; g$ is the gravitational acceleration, $9.8 \mathrm{~m} / \mathrm{s}^{2} ; h$ is the thickness of the failed lay strata on the in-situ model, $50 \mathrm{~m} ; m$ is the compensating quality of iron, $\mathrm{kg}$; and $S_{m}$ is the contact area, $S_{\mathrm{m}}=3000 \times 400 \mathrm{~mm}^{2}=1.2 \mathrm{~m}^{2}$. According to Eq. (1), the iron quality imposed on top of the model is $500 \mathrm{~kg}$.

The selection of the equivalent materials needs to follow the main feature similarity between the insitu model and the material. The physical and mechanical properties noticeably changed with the 


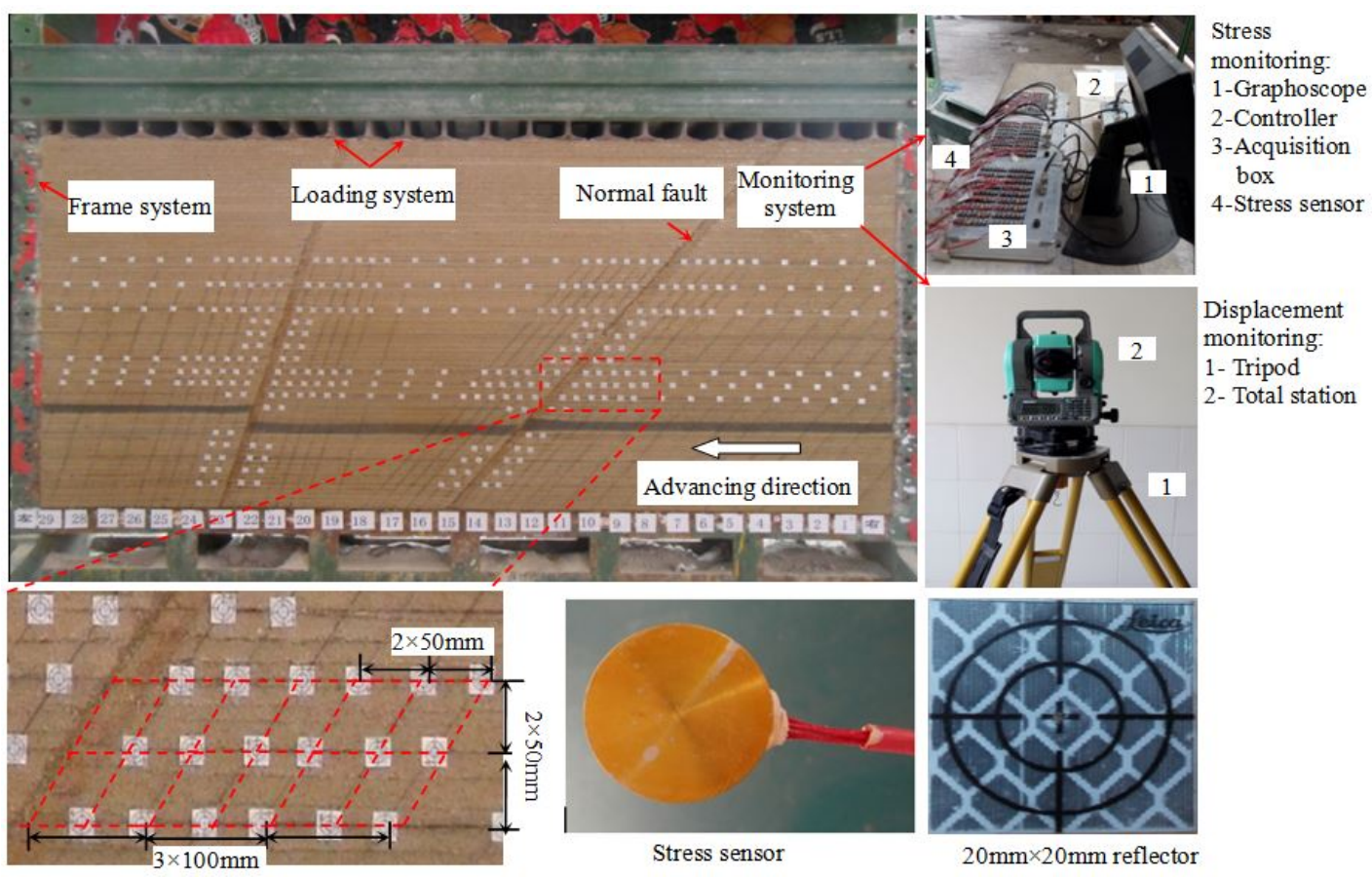

Fig. 2 Physical model and monitoring equipment.

Table 1 Lithology and physical mechanical parameters of the roof and the floor.

\begin{tabular}{lccccccc}
\hline Lithology & \multicolumn{2}{c}{ Density } & \multicolumn{2}{c}{ Compression strength } & \multicolumn{2}{c}{ Elastic modulus } & Material \\
& \cline { 2 - 6 } & $\begin{array}{c}\text { In-situ model } \\
\left(\mathrm{kg} \cdot \mathrm{m}^{-3}\right)\end{array}$ & $\begin{array}{c}\text { Physical model } \\
\left(\mathrm{kg} \cdot \mathrm{m}^{-3}\right)\end{array}$ & $\begin{array}{c}\text { In-situ } \\
\text { model } \\
(\mathrm{MPa})\end{array}$ & $\begin{array}{c}\text { Physical } \\
\text { model } \\
(\mathrm{kPa})\end{array}$ & $\begin{array}{c}\text { In-situ } \\
\text { model } \\
(\mathrm{GPa})\end{array}$ & $\begin{array}{c}\text { Physical } \\
\text { model } \\
(\mathrm{MPa})\end{array}$ \\
\hline Siltstone & 2400 & 1600 & 27.60 & 92.00 & 4.56 & 15.20 & 755 \\
Packsand & 2400 & 1600 & 31.50 & 105.00 & 5.04 & 16.80 & 782 \\
Gritstone & 2400 & 1600 & 36.00 & 120.00 & 4.86 & 16.20 & 773 \\
Coal & 2400 & 1600 & 16.00 & 53.30 & 2.34 & 7.80 & 864 \\
Mudstone & 2250 & 1500 & 17.20 & 57.40 & 2.94 & 9.80 & 864 \\
Sandy mudstone & 2250 & 1500 & 21.10 & 70.30 & 2.94 & 9.80 & 864 \\
Silty mudstone & 2250 & 1500 & 17.20 & 57.40 & 2.94 & 9.80 & 864 \\
\hline
\end{tabular}

different material dosages. They should also have the advantages of stable performance, low cost, and easy production. Therefore, river sand, calcium carbonate, and gypsum were chosen as the physical model materials to simulate the properties of different lithologies with different proportions. Mica powder with a certain thickness was evenly paved between the strata to simulate the rock layer stratification. Material ratio is defined as the different proportion combinations of materials, which is an important factor in the model test. The employed material ratios are listed in Table 1 after Li (1988).

Considering the fault as a weak plane (Huang et al., 2009; Jiang et al., 2017), a plane of mica powder with $10 \mathrm{~mm}$ thickness was built to simulate the fault.

\subsection{SETUP PROCESS OF THE PHYSICAL MODEL}

The following is the setup process for the physical model:

Step I: A model frame system is built, and two steel strips with $2 \mathrm{~mm}$ thickness, $50 \mathrm{~mm}$ width, and $1800 \mathrm{~mm}$ length are installed to assure the dip angle of faults (Fig. 3).
Step II: First, the materials are blended and mixed with caution after weighing, then the model is set up by paving each layer from bottom to top to make it solid. Redundant materials must be removed to meet the model design. Figure 4 shows the modelmaking process. The frames and the steel strips are removed after $7 \mathrm{~d}$ of drying.

\subsection{MONITORING ARRANGEMENT AND MODEL EXCAVATION}

As shown in Figure 2, a grid mesh with a size of $100 \mathrm{~mm} \times 100 \mathrm{~mm}$ was setup for the entire model, while the fault regions were highlighted with a dense mesh of $50 \mathrm{~mm} \times 50 \mathrm{~mm}$. A total of 16 horizontal monitoring lines were set and marked as D1-D16. Reflectors and the Nikno Nivo 2M Electronic Total Station were utilized for displacement monitoring. Table 2 gives the position information of the D7-D16 monitoring lines. Meanwhile, 35 stress sensors were employed for stress monitoring, 19 of which (S1-S19) were buried on the floor of the coal seam to monitor the abutment stress. The other 16 (S20-S35) were 


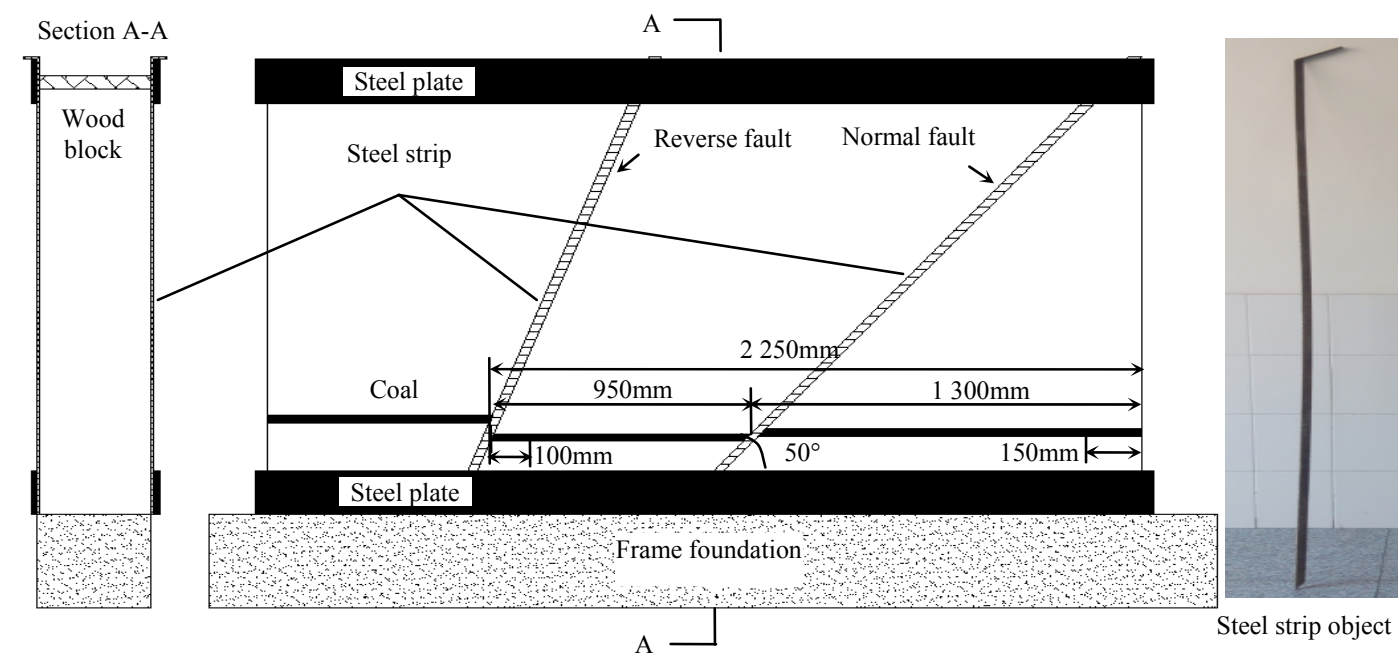

Fig. 3 Position of the steel strips.
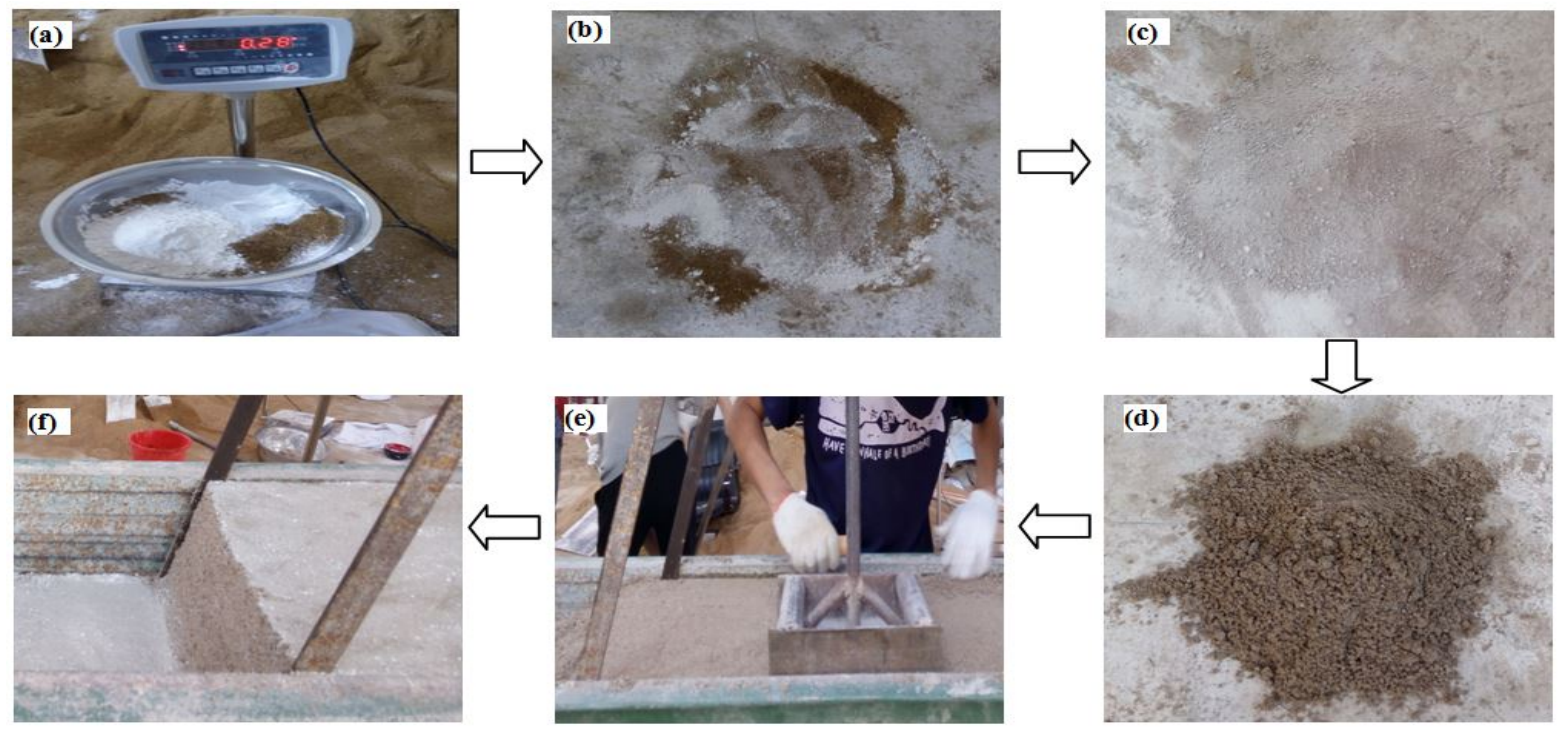

Fig. 4 Physical model-making process: (a) material weighing, (b) material mixing, (c) even blending, (d) water addition and even mixing, (e) paving and ramming, and (f) redundant material removal.

buried along the normal fault in eight vertical layers (L1-L8) (Fig. 5). All the stress sensors were connected to the DH3815N Stress-Strain Testing System with a $10 \mathrm{~s}$ data acquisition interval. Table 3 presents the advancing distance and the corresponding time of mining.

Two straight steel rulers were used to synchronously excavate from the front and rear sides of the model to ensure the model's synchronous movement. The excavation length of the model was $2000 \mathrm{~mm}$, simulating the in-situ excavation $400 \mathrm{~m}$ in strike. Accordingly, $50 \mathrm{~mm}$ in the model strike was excavated, and the interval time between the two excavations was $2 \mathrm{~h}$. The experiment results were obtained from displacement and stress monitoring and photo recording.

\section{FAILURE-MOVEMENT EVOLUTION LAWS OF OVERLYING STRATA}

The intensive mining operation of the longwall mining method leads to massive failure and fracturing of the overlying strata, thereby forming a fractured zone, whose extent is a crucial parameter in evaluating hazardous accidents, such as roof water inrush, gas flow, and outburst (Zeng et al., 2006). Obtained from the photo recording and the displacement monitoring, Figure 6 shows the evolution of the overlying strata with respect to the distance to the fault during the mining operation simulation. Note that all the length parameters were converted to in-situ scale.

\subsection{FAILURE PROCESS OF THE OVERLYING STRATA}

The entire failure and movement process of the overlying strata with the advancing excavation can be divided into six stages as follows: 
Table 2 Position information of the D7-D16 monitoring lines of the overlying strata.

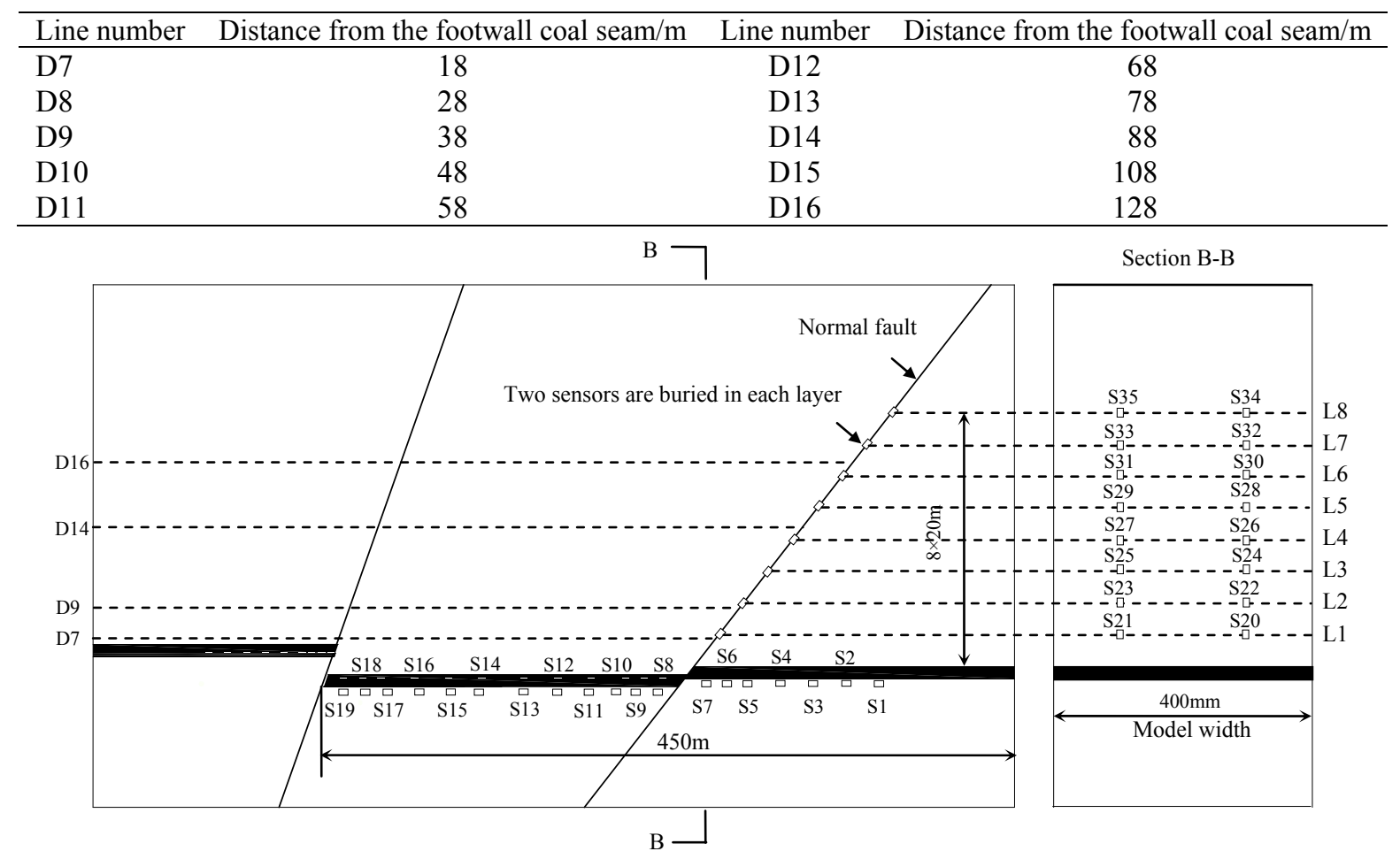

Fig. 5 Arrangement of the stress sensors.

Table 3 Monitoring data of stress during model mining.

\begin{tabular}{cccc}
\hline $\begin{array}{c}\text { Distance between excavation } \\
\text { and the fault/m }\end{array}$ & Mining time/s & $\begin{array}{c}\text { Distance between excavation and } \\
\text { the fault } / \mathrm{m}\end{array}$ & Mining time/s \\
\hline 40 & $87,206-109,616$ & 0 & $135,002-144,414$ \\
30 & $109,626-116,983$ & -30 & $215,547-242,431$ \\
20 & $116,993-127,732$ & -70 & $248,400-251,278$ \\
10 & $127,742-134,992$ & -110 & $284,887-292,734$ \\
\hline
\end{tabular}

Stage I: the distance between the excavation face and the normal fault is over $40 \mathrm{~m}$ (i.e., $L \geq 40 \mathrm{~m}$ ). As can be seen from Figures $6 a$ and $6 b$, with the advancing excavation, a typical three-zone structure (i.e., caved zone, fractured zone, and continuous deformation zone) is found over the extracted seam in ascending order from the roofline (Peng and Chiang, 1984). The key stratum and its surrounding strata move together with the periodic caving of the immediate roof, and bed separation appears under the key strata and continuously upward. The height of the mining-induced fracture extends from $58 \mathrm{~m}$ to $84 \mathrm{~m}$ as the distance between the face and the fault decreases from $80 \mathrm{~m}$ to $40 \mathrm{~m}$. A saddle-shaped fracture channel is also observed in the overlying strata.

Stage II: $40 \mathrm{~m}>L>0 \mathrm{~m}$. The fractured zone continues to develop, and the height of the mininginduced fracture increases from $130 \mathrm{~m}$ to $174 \mathrm{~m}$. The strata near the fault rotate to the goaf because of the effect of the fault and its dip angle. The fault then gradually opens. After $L$ is less than $20 \mathrm{~m}$, the mininginduced fractured zone connects with the fault, and the movement of overlying strata is marked in Figure 6e.

Stage III: $L=0 \mathrm{~m}$. The excavation face reaches the fault plane; a sudden subsidence of the footwall overlying strata is observed, and the fault fully opens along its dip direction. A trapezium-shaped fracture channel also occurs (Fig. 6f).

Stage IV: $0 \mathrm{~m}>L \geq-30 \mathrm{~m}$. The negative value indicates the distance between the excavation face and the normal fault after the face has passed the fault. With the caving of the hanging-wall immediate roof, the suspended main roof rotates to the fault and collapses, leading to the closure of the fault with the low water permeability below the main roof, while the higher part of the fault retains water permeability. Consequently, an M-shaped fracture channel occurs (Fig. 6g).

Stage V: $-30 \mathrm{~m}>L \geq-70 \mathrm{~m}$. As the excavation face advances further ahead of the fault (Fig. 6h), the overlying strata slip under the effect of fault and overburden pressure, causing the fault closure, the increase of the mining-induced fracture height of the hanging wall to $72 \mathrm{~m}$, and that of footwall rises to $178 \mathrm{~m}$.

Stage VI: $-70 \mathrm{~m}>L$. The caved rock in the hanging wall forms a support structure for the overlying strata, which leads to the minor effect of the fault on the strata movement. The height of the fracture channel remains to be $72 \mathrm{~m}$ (Fig. 6i). 


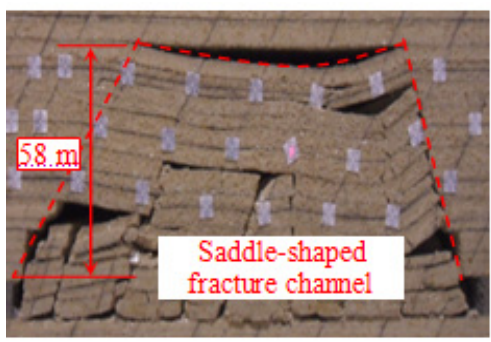

(a)

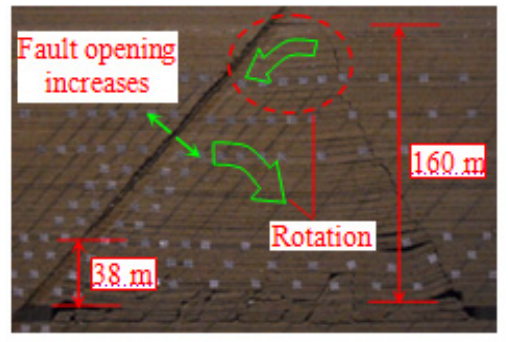

(d)

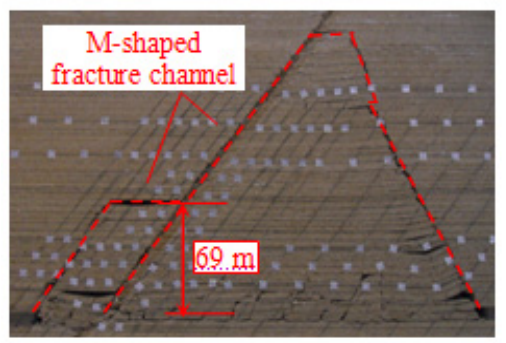

(g)

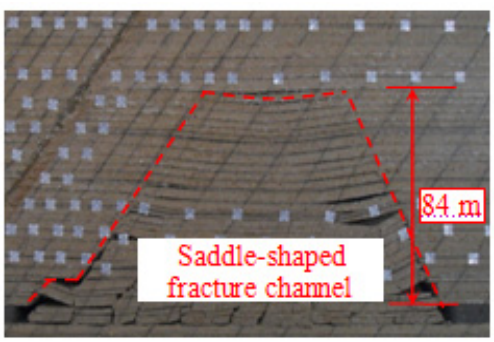

(b)

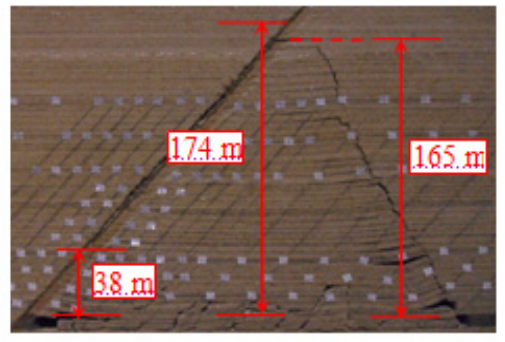

(e)

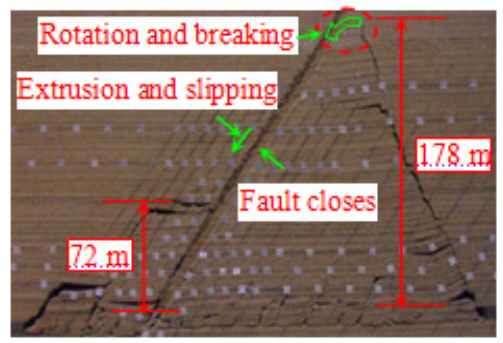

(h)

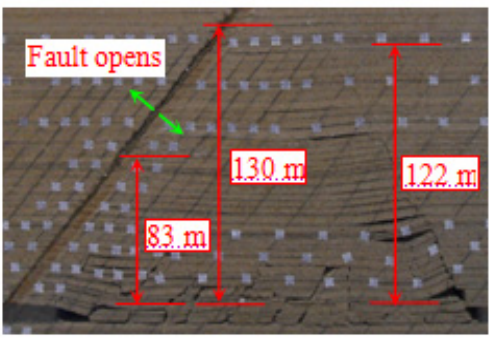

(c)

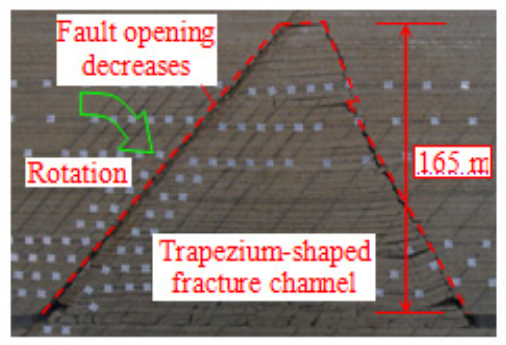

(f)

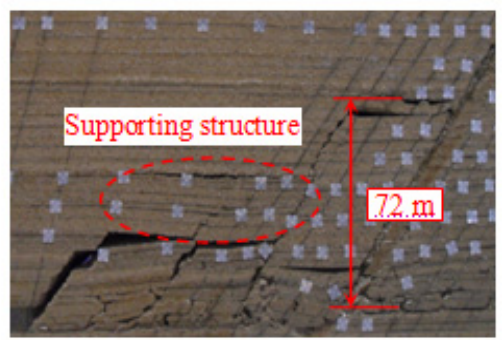

(i)

Fig. 6 Failure process of the overlying strata: (a) $L=80 \mathrm{~m}$; (b) $L=40 \mathrm{~m}$; (c) $L=30 \mathrm{~m}$; (d) $L=20 \mathrm{~m}$; (e) $L=10 \mathrm{~m}$; (f) $L=0 \mathrm{~m}$; (g) $L=-30 \mathrm{~m}$; (h) $L=-70 \mathrm{~m}$; and (i) $L=-110 \mathrm{~m}$.

\subsection{MOVEMENT LAW OF THE OVERLYING STRATA}

The subsidence curves of the overlying strata at different layers based on the D7, D9, D14, and D16 monitoring data were obtained as shown in Figure 7.

Figure 7 shows that in stage I $(L \geq 40 \mathrm{~m})$, the displacement of the footwall strata was in the typical basin-type subsidence. The subsidence range and values decreased from D7 to D16, and the maximum values were $7,5.7,2.2$, and $1.6 \mathrm{~m}$, respectively, when $L=40 \mathrm{~m}$.

In stage II $(40 \mathrm{~m}>L>0 \mathrm{~m})$, the subsidence values of the D14 and D16 lines on the footwall increased with the advancing excavation. Moreover, the maximum values suddenly rose to 5.4 and $5 \mathrm{~m}$ when $L=10 \mathrm{~m}$. A small subsidence appeared on the hanging wall strata with the same maximum values of $1.2 \mathrm{~m}$ because of the rotation of the cantilever strata. The maximum values of the D7 and D9 lines on the footwall slightly increased to 7.2 and $5.8 \mathrm{~m}$, respectively. The hanging wall strata still had no subsidence.

In stage III $(L=0 \mathrm{~m})$, the excavation face reached the fault plane; the subsidence range of the D7 and D9 lines on the footwall continued to expand; and both lines on the hanging wall began to subside with the same maximum values of $1.2 \mathrm{~m}$ because of the rotation of the cantilever strata. However, the subsidence of the D14 and D16 lines had no remarkable changes because the high-located strata completely moved.

In stage IV $(0 \mathrm{~m}>L \geq-30 \mathrm{~m})$, the subsidence of all the lines on the footwall was stable because the footwall strata had completely moved when $L=$ $-30 \mathrm{~m}$. However, the maximum values of the D7 and D9 lines on the hanging wall rapidly increased to 5.2 and $4.8 \mathrm{~m}$, respectively, because the suspended main roof rotated to the fault and collapsed, and those of the D14 and D16 lines slightly increased.

In stage $\mathrm{V}(-30 \mathrm{~m}>L \geq-70 \mathrm{~m})$, as the excavation face advanced further, the footwall strata movement was influenced by the rotation and extrusion of the hanging wall strata. Both subsidence values of the D14 and D16 lines increased to $5.4 \mathrm{~m}$ when $L=-70 \mathrm{~m}$. The maximum values of the D14 and D16 lines on the hanging wall increased to the same $3 \mathrm{~m}$.

Hence, in conclusion, under this test condition, the movement of the strata of the two fault walls had a remarkable difference. The footwall strata fully moved compared to the hanging wall. Thus, the 


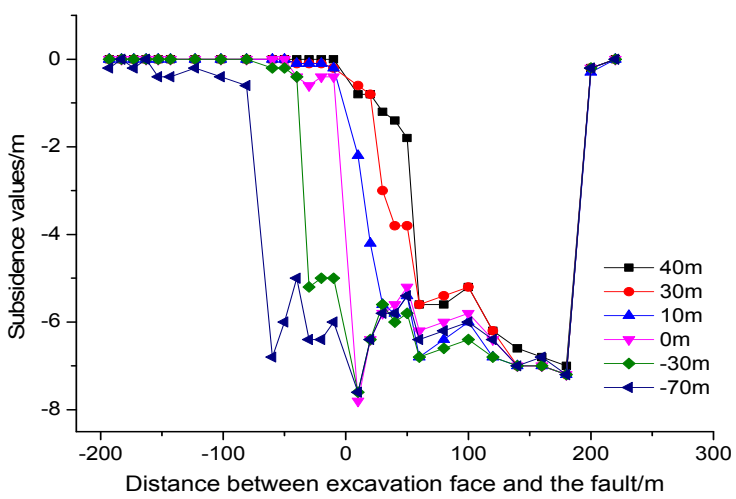

(a)

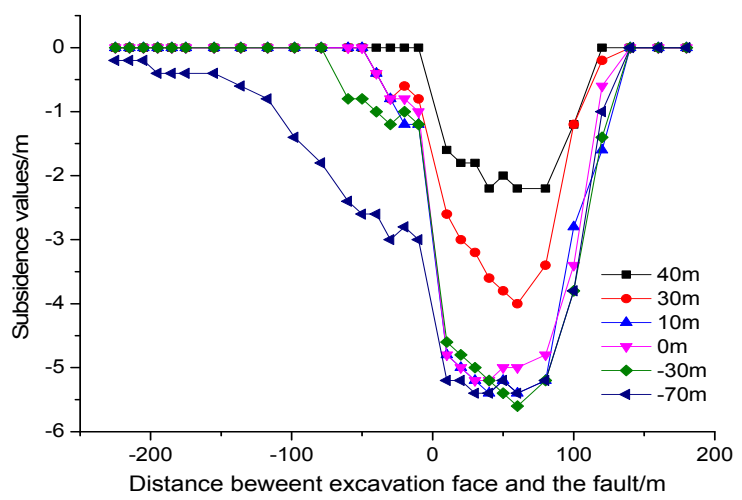

(c)

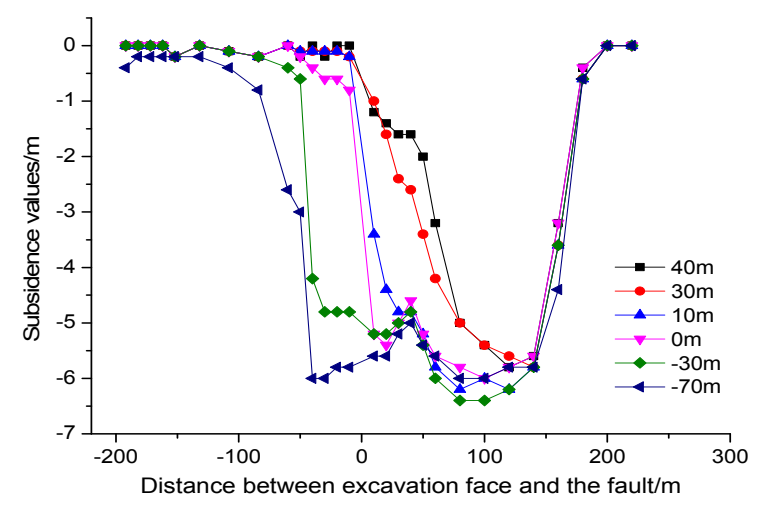

(b)

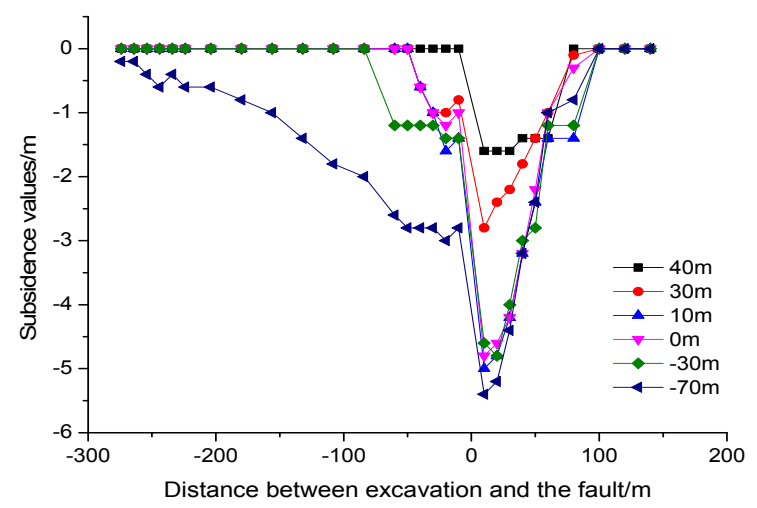

(d)

Fig. 7 Subsidence curves of the overlying strata at different layers: (a) D7 monitoring line, (b) D9 monitoring line, (c) D14 monitoring line, and (d) D16 monitoring line.

mining-induced fracture height was higher than that of the hanging wall.

\section{STRESS EVOLUTION AND SLIPPING LAWS ON THE FAULT PLANE \\ 4.1. NORMAL STRESS EVOLUTION OF THE FAULT PLANE}

The fault plane stress changes with the mining activity. Hence, the normal stress of the fault plane was analyzed based on the data of the S20-S35 sensors in the L1-L8 layers (Fig. 8).

When the mining time was $87,206 \mathrm{~s}-116,983 \mathrm{~s}$, which indicated $40 \mathrm{~m} \geq L \geq 30 \mathrm{~m}$ according to Table 3, the average normal stress of S34 and S35 in the L8 layer ranged from -0.01 to $0 \mathrm{MPa}$ (Fig. 8). The normal stress in the L4-L8 layers then decreased because the fault opened when $L=30 \mathrm{~m}$. When the mining time was $116,983 \mathrm{~s}-144,414 \mathrm{~s}(30 \mathrm{~m}>L \geq$ $0 \mathrm{~m}$ ), the normal stress of the L1-L3 layers increased, and the peak stress values were $0.014 \mathrm{MPa}$, $0.010 \mathrm{MPa}$, and $0.010 \mathrm{MPa}$, respectively, because of the compression of the rotating lower strata. The stress then rapidly dropped because the fault fully opened when $L=0 \mathrm{~m}$. When the mining time exceeded 144,414 s (0 m > L ), the normal stress of all the layers gradually rose and became moderate, indicating that the fault gradually closed, and the overlying strata tended to be stable.

\subsection{RELATIVE SUBSIDENCE ANALYSIS OF BOTH SIDES OF THE FAULT}

Figure 9 presents the subsidence curves of the two monitoring lines parallel to the fault plane.

Figures $9 \mathrm{a}$ and $9 \mathrm{~b}$ depict that both the subsidence in the footwall and the hanging wall generally increased with the advancing excavation face. However, the subsidence characteristics differed. As can be seen in Figure $9 \mathrm{a}$, when $L \geq 10 \mathrm{~m}$, the subsidence gradually decreases as the monitoring point moves from a higher to a lower location in the strata. The monitoring points in the higher strata were closer to the advancing face because of the dip of the fault. When $L=0 \mathrm{~m}$, a sudden drop of the subsidence caused by the support loss of the coal seam can be observed in the footwall, while the hanging wall was not significantly affected. A notable subsidence occurred to all the monitoring points of the footwall measuring line after the face passed over $30 \mathrm{~m}$ from the fault $(-30 \mathrm{~m}>L)$. Meanwhile, a significant difference was observed in the hanging wall between the monitoring points lower and higher to $60 \mathrm{~m}$ from the coal seam vertically. Agreeing with the failure and movement laws in Section 3, the footwall strata integrally sank, while bed separations occurred in the hanging wall strata, causing a subsidence difference in the low and high regions of the hanging wall strata. 


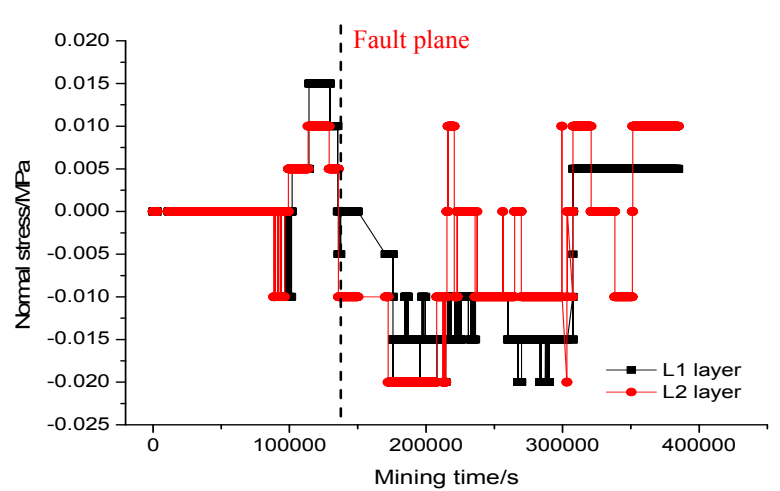

(a)

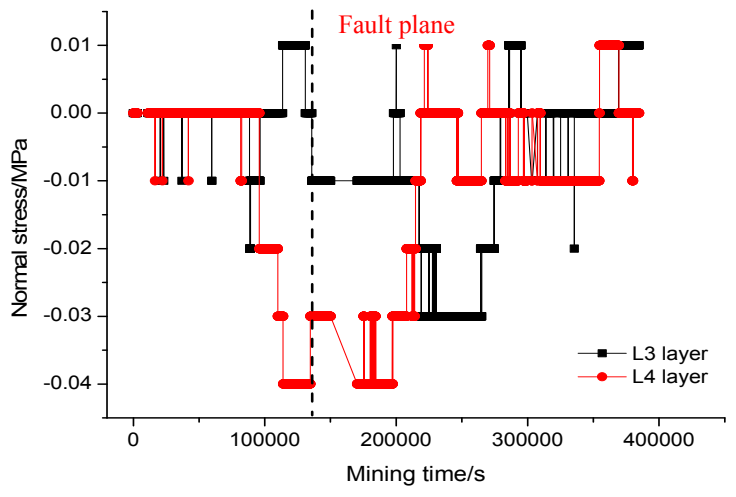

(b)

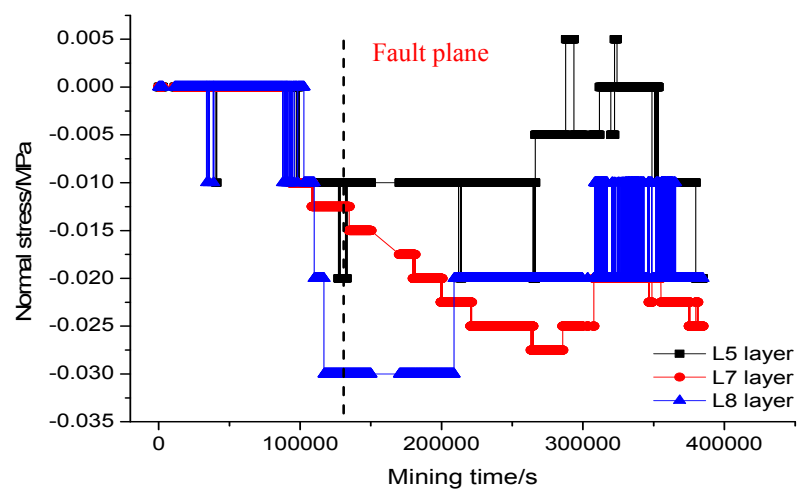

Fig. 8 Normal stress distribution of the fault plane.

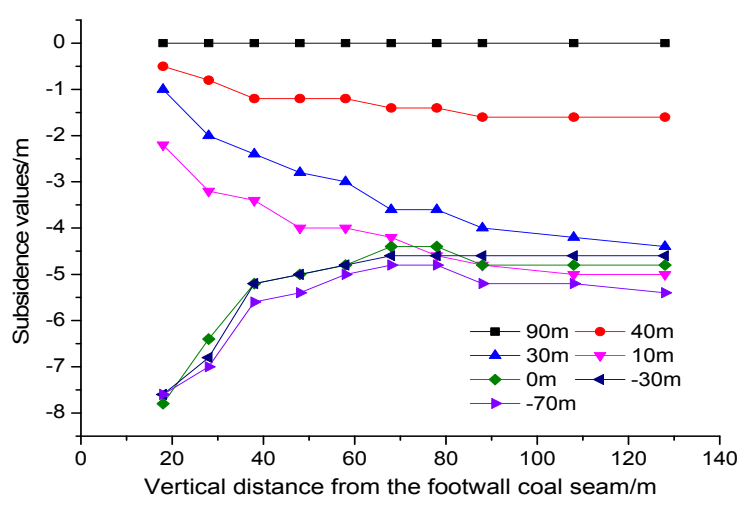

(a)

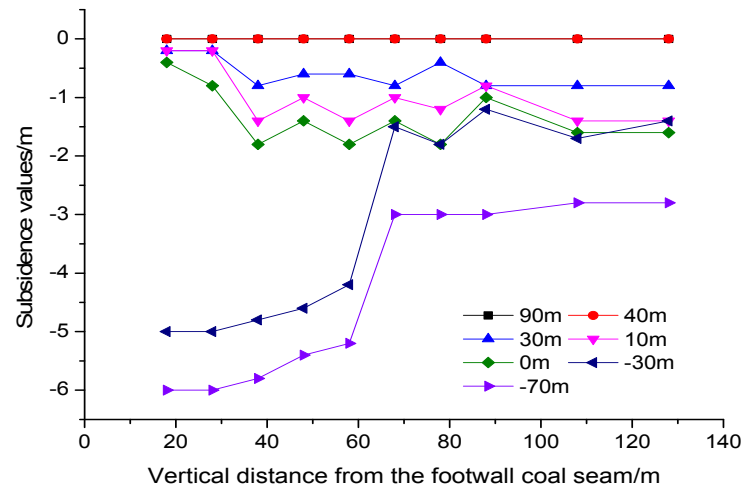

(b)

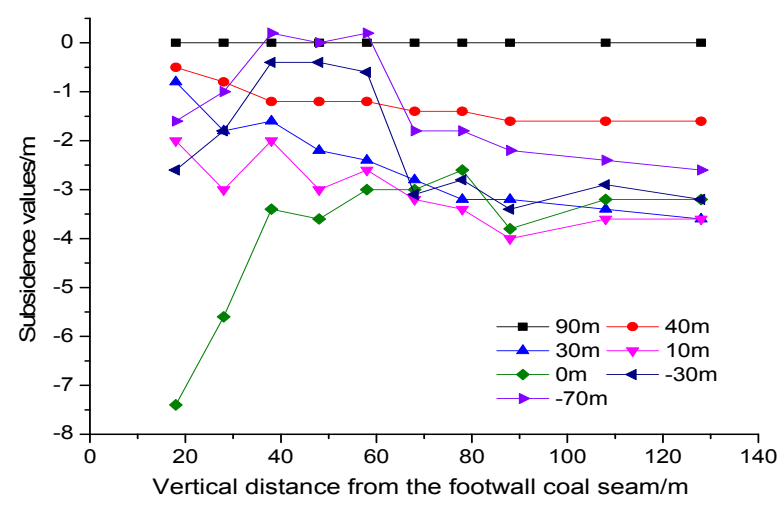

(c)

Fig. 9 Subsidence curves of both sides of the fault: (a) footwall monitoring line, (b) hanging wall monitoring line, and (c) relative subsidence of the two fault walls. 


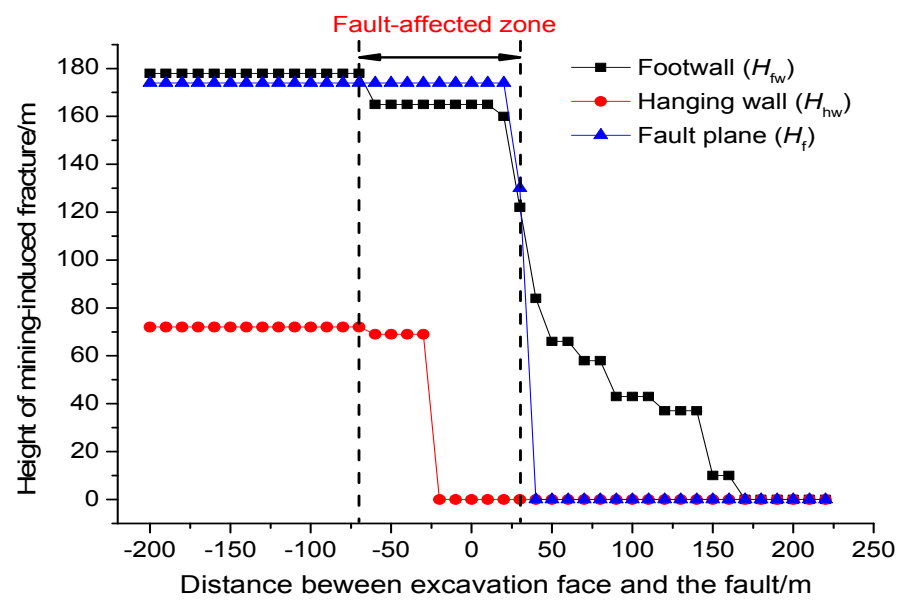

Fig. 10 Mining-induced fracture height of the two fault walls and the fault plane.

\section{EVOLUTION LAWS OF THE OVERLYING STRATA FRACTURE}

\subsection{EVOLUTION LAWS OF THE OVERLYING STRATA FRACTURE}

Figure 10 shows the relationship between the mining-induced fracture heights and the advancing process of the face considering the vertical distance between the top of the fractured zone and the coal seam as the mining-induced fracture height of the footwall and the hanging wall $\left(H_{\mathrm{fw}}\right.$ and $\left.H_{\mathrm{hw}}\right)$ and the vertical distance between the top of the opening fracture of the fault and the coal seam as the mininginduced fracture height of the fault $\left(H_{\mathrm{f}}\right)$.

Note that $H_{\mathrm{fw}}, H_{\mathrm{hw}}$, and $H_{\mathrm{f}}$ monotonically increased with the advancing face. The effect of the mining activities on the mining-induced fracture height first occurred in the footwall. The height increase then gradually accelerated with the advancing face, and a sharp increase can be observed at $L=$ $30 \mathrm{~m}$, where $H_{\mathrm{fw}}$ rises to $165 \mathrm{~m}$, and $H_{\mathrm{f}}$ rises to $174 \mathrm{~m}$. $H_{\text {hw }}$ increased to $69 \mathrm{~m}$ when $L=-30 \mathrm{~m}$. Both $H_{\mathrm{fw}}$ and $H_{\mathrm{hw}}$ then remained constant afterwards. However, when $L<-30 \mathrm{~m}$, the normal fault re-closed with the subsidence of the hanging wall strata, and the fault conductivity became very low according to the monitoring data of the two fault walls from Sections 3 and 4.

Thus, in conclusion, the fault had a notable effect on the mining-induced fracture evolution, which had the most significant effect within $30 \mathrm{~m} \geq L \geq-70 \mathrm{~m}$.

\subsection{DEVELOP PATTERNS OF THE FRACTURE CHANNEL}

The mining-induced fracture distribution and the fracture channel patterns of the overlying strata presented particularity under the effect of the fault and the fracture channel morphological evolution of the overlying strata (Fig. 11; (Zeng et al., 2006)).

Figure 11 presents sketches of the mininginduced fracture evolution based on the results presented in Sections 3 and 4. As can be seen from Figure 11a, the fault was not affected by mining, and the large bed separation appeared under the key strata when $L \geq 40 \mathrm{~m}$. A typical "saddle-shaped" fracture channel also occurred on the footwall enveloped by the overlying breaking lines and bed separation.

Figure $11 \mathrm{~b}$ illustrates that when $L=30 \mathrm{~m}$, the fault began to be affected by mining, and the fault plane opened at $83-130 \mathrm{~m}$ in the vertical direction. The bed separation still had not interconnected with the fault zone.

Figure 11c shows that the fault plane fully opens (marked with a red dotted line) with the sudden subsidence of the footwall low-located strata. The bed separation also developed upwards when $L=0 \mathrm{~m}$, and a "trapezium-shaped" fracture channel occurred.

As shown in Figure 11d, the lower part of the fault re-closed, while the higher part remained open when $L=-30 \mathrm{~m}$ because of the movement of the hanging wall strata, which led to an "M-shaped" fracture channel (marked with a blue line). The reclosed fault could sometimes actually allow the ingress of water or gas caused by the interlocking imperfect asperities. However, the subsidence of the hanging wall strata will significantly decrease the fault's conductivity. Hence, the conductivity of the fault may become very low according to observation and data.

\section{DISCUSSION OF THE ACCIDENTS CAUSED BY THE MINING-INDUCED FRACTURE}

Coal extraction induces stress readjustment surrounding the strata failure and movement under which circumstance, the mining-induced fractured zone occurs. The strata movement loses consistency under the effect of faults. Meanwhile, faults are activated because of the strata movement, leading to the extension of the mining-induced fracture and hazardous potential, such as roof water inrush, gas flowing and outburst and so on (Wang et al., 2015b; Li et al., 2016).

Figure 12 shows the discussion of the aforementioned accidents caused by the mininginduced fracture based on the presented research 


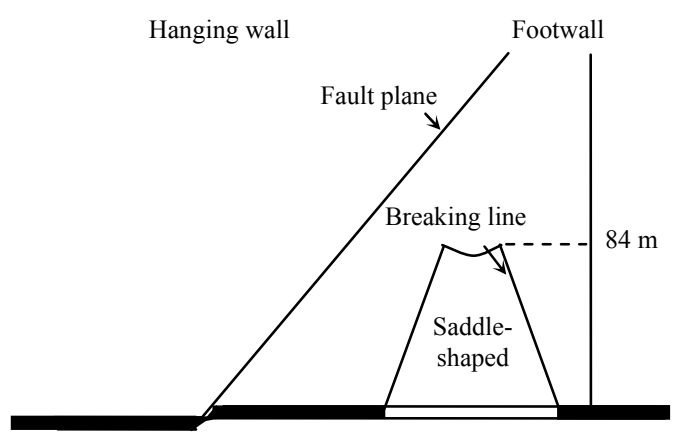

(a)

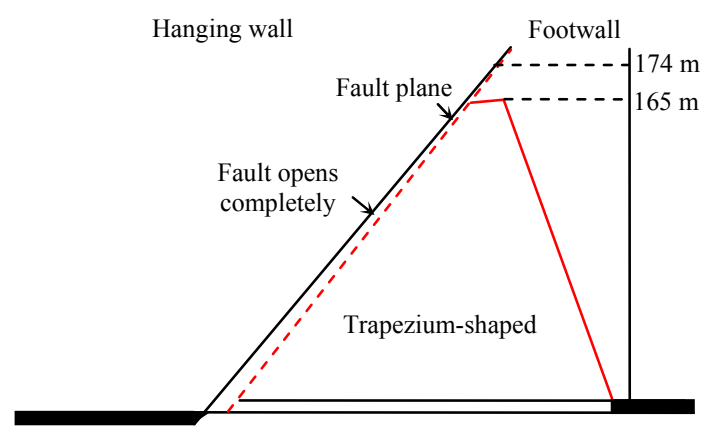

(c)

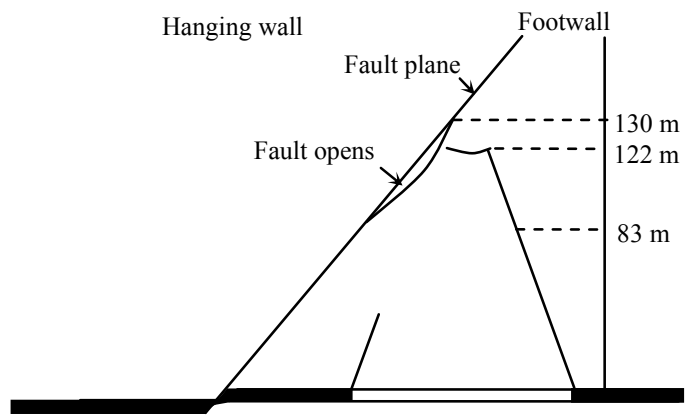

(b)

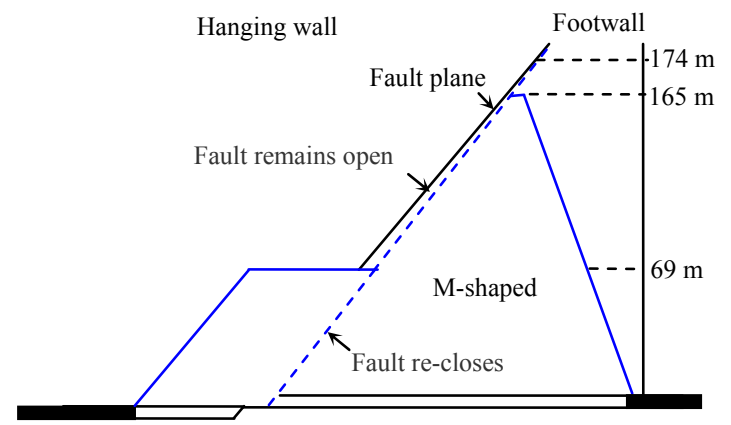

(d)

Fig. 11 Develop patterns of the fracture channel: (a) $L=40 \mathrm{~m}$; (b) $L=30 \mathrm{~m}$; (c) $L=0 \mathrm{~m}$; and (d) $L=-30 \mathrm{~m}$.

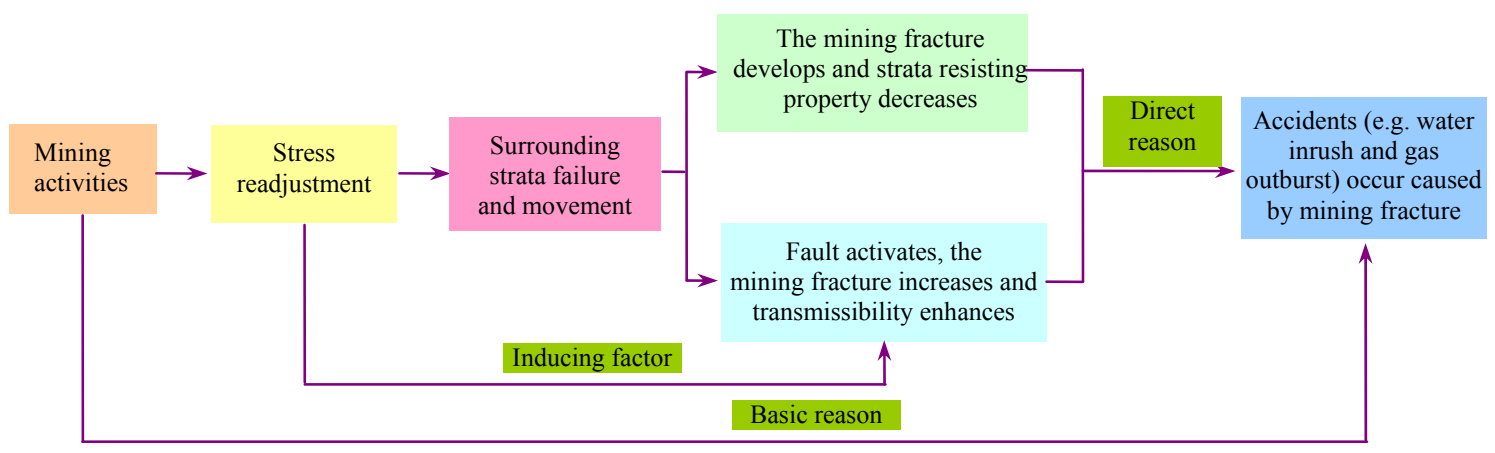

Fig. 12 Discussion of the accidents caused by the mining-induced fracture.

results. The direct reason for the fault-affected underground coalmine is the extension of the mininginduced fracture caused by the fault activation, which might provide reference for studies on the prevention of water inrush or gas outburst under similar ground conditions.

\section{CONCLUSIONS}

A physical simulation test of a progressive mining operation with the occurrence of a normal fault was performed in this study. The failuremovement evolution of the overlying strata and the stress-displacement evolution of the fault were studied. Moreover, the formation of the mininginduced fracture and the mechanism of accidents (e.g., water inrush, gas flowing and outburst) caused by the mining-induced fracture were analyzed accordingly.

Under the effect of the normal fault, it can be concluded that the footwall strata undergo a more notable movement compared to the hanging wall strata; hence, the mining-induced fracture height of the footwall is higher than that of the hanging wall. The effect of the fault can be observed on the mininginduced fracture evolution of the footwall, hanging wall, and fault plane. The effect is most significant within $30 \mathrm{~m} \geq \mathrm{L} \geq-70 \mathrm{~m}$, where $\mathrm{L}$ is the distance between the excavation face and the fault, and the negative value indicates that the excavation face has passed the fault. The developed patterns of the fracture channel successively present an evolution in the shape of a "saddle" ( $\mathrm{L}>30 \mathrm{~m})$, a "trapezium" $(\mathrm{L}=0 \mathrm{~m})$, and an "M" $(\mathrm{L}=-30 \mathrm{~m})$. Finally, the causes of hazardous accidents induced by the mining fracture are analyzed and discussed.

The results can be utilized for studying the mining-induced behaviors of faults and strata in underground coalmines and are highly significant for understanding the mechanism and prediction of accidents caused by a mining-induced fracture. 


\section{ACKNOWLEDGMENTS}

This study was funded by the National Natural Science Foundation of China (nos. 51574155, 51374139, 51704182, 51704185, and 51504145), the Natural Science Foundation of Shandong Province (Nos. ZR2017BEE050 and ZR2017BEE045), the Shandong Provincial Key R\&D Plan (Public Welfare Special Program) of China (no. 2017GGX20125), the Tai'an Science and Technology Development Plan of Shandong Province (No. 2015ZC1058), the Science and Technology Innovation Fund of College of the Mining and Safety Engineering, Shandong University of Science and Technology (No. KYKC17008).

\section{REFERENCES}

Blenkinsop, T.G.: 2008, Relationships between faults, extension fractures and veins, and stress. J. Struct. Geol., 30, No.5, 622-632. DOI: 10.1016/j.jsg.2008.01.008

Dai, H.Y., Lian, X.G., Liu, J.Y., Liu, Y.X., Zhou, Y.M., Deng, W.N. and Cai, Y.F.: 2010, Model study of deformation induced by fully mechanized caving below a thick loess layer. Int. J. Rock Mech. Min. Sci., 47, No.6, 1027-1033.

DOI: $10.1016 /$ j.ijrmms.2010.06.005

Ding, H.D., Miao, X.X., Ju, F., Wang, X.L. and Wang, Q.C.: 2014, Strata behavior investigation for highintensity mining in the water-rich coal seam. Int. J. Min. Sci. Technol., 24, No. 3, 299-304.

DOI: $10.1016 /$ j.ijmst.2014.03.002

Fan, Z.L.: 2014a, The influence of different fault throws to the height of water-flowing fractured zone. Adv. Mater. Res., 1073-1076, 2088-2091. DOI: 10.4028/www.scientific.net/AMR.1073-1076.2088

Fan, Z.L.: 2014b, Research on the influence by different dip angles faults of the damage height of superincumbent stratum. App. Mech. Mater., 675-677, 1421-1424. DOI: 10.4028/www.scientific.net/AMM.675-677.1421

Hu, G.: 2008, Study on the water transmitting mechanism while fault activated in fully mechanized top-coal caving. Ph.D. Thesis, China University of Mining and Technology, Xuzhou, 66 pp., (in Chinese).

Huang, B.X., Liu, C.Y. and Xu, J.L.: 2009, Effect of little fault in working face on water conducted fissure height. J. China Coal Soc., 34, No. 10, 1316-1321, (in Chinese). DOI: 10.13225/j.cnki.jccs.2009.10.016

Huang, Y.L., Zhang, J.X., An, B.F. and Zhang, Q.: 2011, Overlying strata movement law in fully mechanized coal mining and backfilling longwall face by similar physical simulation. J. Min. Sci., 47, No. 5, 618-627. DOI: $10.1134 / \mathrm{S} 1062739147050108$

Jiang, L.S., Sainoki, A., Mitri H.S., Ma, N.J., Liu, H.T. and Hao, Z.: 2016, Influence of fracture-induced weakening on coal mine gateroad stability. Int. J. Rock Mech. Min. Sci., 88, 307-317. DOI: $10.1016 /$ j.ijrmms.2016.04.017

Jiang, L.S., Wang, P., Zhang, P.P., Zheng, P.P. and Xu, B.: 2017, Numerical analysis of the effects induced by normal faults and dip angles on rock bursts. Compte. Rendu. Mecanique, 345, No. 10, 690-705.

DOI: 10.1016/j.crme.2017.06.009

Jiang, J.Q., Wang, P., Zheng, P.Q. and Wu, Q.L.: 2017, Evolution characteristics of mining-induced fracture and abutment stress under high-position hard thick stratum and its effect on gas migration. J. Min. Safe. Eng., 34, No.4, 624-631, (in Chinese).

DOI: $10.13545 /$ j.cnki.jmse.2017.04.003

Lai, X.P., Shan, P.F., Cao, J.T., Cui F., and Sun, H.: 2016, Simulation of asymmetric destabilization of mine-void rock masses using a large 3D physical model. Rock
Mech. Rock Eng., 49, No. 2, 487-502.

DOI: $10.1007 / \mathrm{s} 00603-015-0740-\mathrm{z}$

Li, H.C.: 1988, Similar simulation test for ground pressure. China University of Mining and Technology Press, Xuzhou, 103 pp., (in Chinese).

Li, T., Mu, Z.L., Liu, G.J., Du, J.L. and Lu, H.: 2016, Stress spatial evolution law and rock burst danger induced by coal mining in fault zone. Int. J. Min. Sci. Technol., 26, No. 3, 409-415. DOI: 10.1016/j.ijmst.2016.02.007

Lin, H.F.: 2009, Study on the law of mining-induced fracture evolution of overlying strata and relieved methane delivery and its engineering application in fully-mechanized top coal caving. Ph.D. Thesis, Xi'an University of Science and Technology, Xi`an, 29 pp., (in Chinese).

Liu, Y.K., Zhou, F.B., Liu, L., Liu, C. and Hu, S.Y.: 2011, An experimental and numerical investigation on the deformation of overlying coal seams above doubleseam extraction for controlling coal mine methane emissions. Int. J. Coal Geol., 87, No.2, 139-149. DOI: $10.1016 /$ j.coal.2011.06.003

Peng, S.S., and Chiang, H.S.: 1984, Longwall mining. Wiley, New York, 708 pp.

Wang, C., Zhang, N.C., Han, Y.F. and Qian, D.Y.: 2015a, Experiment research on overburden mining-induced fracture evolution and its fractal characteristics in ascending mining. Arab. J. Geosci., 8, No. 1, 13-21. DOI: $10.1007 / \mathrm{s} 12517-013-1178-9$

Wang, H.Z. and Ding, H.W.: 2002, Probing into water inrush mechanism in 111311 face of NO.1 Xinji, Mine. Min. Safe. Environ. Protect., 29, No. 1, 24-25, (in Chinese).

Wang, W., Cheng, Y.P., Wang, H.F., Liu, H.Y., Wang, L., Li, W. and Jiang, J.Y.: 2015b, Fracture failure analysis of hard-thick sandstone roof and its controlling effect on gas emission in underground ultra-thick coal extraction. Eng. Failure Anal., 54, 150-162. DOI: 10.1016/j.engfailanal.2015.04.016

Wang, Y.C., Jing, H.W., Yu, L.Y., Su, H.J. and Luo, N.: 2016, Set pair analysis for risk assessment of water inrush in karst tunnels. Bull. Eng. Geol. Environ., 1-9. DOI: 10.1007/s10064-016-0918-y

Xie, J., Zhu, W., Xu, J.L.,Wen, J.H. and Liu, C.Z.: 2016, A study on the bearing effect of pier column backfilling in the goaf of a thin coal seam. Geosci. J., 20, No. 3, $361-369$

DOI: $10.1007 / \mathrm{s} 12303-015-0047-9$

Yin, L.M., Guo, W.J. and Yin, Z.D.: 2009, Study on failure law of overlaying strata under influence of faults. J. Shandong Univ. Sci. Technol. (Natural Science), 28, No. 4, 59-63, (in Chinese). DOI: $10.16452 /$ j.cnki.sdkjzk.2009.04.011

Yin, W., Miao, X.X., Zhang, J.X. and Zhong, S.J.: 2017, Mechanical analysis of effective pressure relief protection range of upper protective seam mining. Int. J. Min. Sci. Technol., 27, No. 3, 537-543. DOI: $10.1016 /$ j.ijmst.2017.03.021

Zeng, X.G., Li, W.P., Li, H.L., Liu, Q.M. and Jiang G.L.: 2006, Development rule of height of water conducted zone near fault with fully mechanized top-coal caving. J. China Univ. Min. Technol., 23, No.3, 306-310, (in Chinese).

Zhen, Y.B., Zhao, Y.C, and Wang, Z.B.: 2013, Study on broken law of roof above coal mining face under influences of fault. Coal Eng., 45, No. 9, 71-74, (in Chinese). DOI: 10. 11799 /ce201309026

Zhou, D.W., Wu, K., Cheng, G.L. and Li, L.: 2014, Mechanism of mining subsidence in coal mining area with thick alluvium soil in China. Arab. J. Geosci., 8, No. 4, 1855-1867. DOI: 10.1007/s12517-014-1382-2 